\title{
Evaluation performance in health regions in Brazil
}

\author{
Liza Yurie Teruya Uchimura 1 \\ Eronildo Felisberto 2 \\ Edgar Rodrigues Fusaro 3 \\ Maria Paula Ferreira 4 \\ Ana Luiza d' Ávila Viana 5
}

\footnotetext{
1,5 Departamento de Medicina Preventiva. Faculdade de Medicina. Universidade de São Paulo. Av. Dr. Arnaldo, $4552^{\circ}$ andar. São Paulo, SP, Brasil. CEP: 01.246-903. E-mail: Iytuchimura@gmail.com

2 Instituto de Medicina Integral Prof. Fernando Figueira. Recife, Pernambuco, Brasil.

3 Departamento Intersindical e Estatística e Estudos Econômicos (DIIESE). São Paulo, SP, Brasil.

4 Fundação Sistema Estadual de Análise de Dados. São Paulo, SP, Brasil.
}

\begin{abstract}
Objectives: To propose a regional synthetic indicator (ISR) to evaluate the health system performance in Brazilian regions based on a national database source available free of charge in a global network of computers.

Methods: a cross-sectional study using secondary data, considered seven variables of five dimensions in the health system (population's health conditions, health system coverage, financing, human resources and SUS production) analyzed from a survey of 438 Brazilian regions and adopted factor analysis and cluster models, conditioned by variables, such as: socioeconomic development, offering and service complexity and which resulted in a grouping of five strata.

Results: mapping and scheduling based on ISR in health regions in Brazil and a detailed analysis of different indicators that compose them. The regions that showed better performance are in the Southeast, South and Midwest.

Conclusions: This article sums efforts of other authors to extend the evaluation studies in health systems in a regional level. In addition, it is expected that the researches broaden their scope and implement the discussions about the process of regionalization in order to provide health policies, a universalized access and care comprehensiveness.
\end{abstract}

Key words Regionalization, Health evaluation, Health management 


\section{Introduction}

\section{The health system performance}

A health system, according to Roemer's ${ }^{1}$ definition is a "combination of resources, organization, financing and managing that culminates in the provision of health services for the population". We emphasize Donabedian's 2 study who developed a model to evaluate the health systems.

Donabedian's ${ }^{2}$ pointed out that the evaluation result represents norms or criteria to be incorporated in the use of the performance indicators, so that they will be replicated and contribute to the improvement of the quality of the system. The author has developed concepts that evaluate the quality of a health system, composed of three axes: the structure, the process and the outcome. The structure describes the attributes of health policies, such as human resources, financing and information systems. The process characterizes the care that is offered. The result presents the impact in relation to the efficiency and quality of the health service.

More recent publications emphasize a broader view of the performance evaluation of health systems - this is Klazinga's ${ }^{3}$ case which considers elements such as accountability, capacity of strategic decision-making and the dyad of "learning and improvement" as basic goals and comparative studies. On the other hand, Canadian authors propose an integrator model to evaluate the performance, which consists in the adoption of a balanced form of four major functions that an organized system of action must meet: the adaptation; target achievements; production; and preservation of values. 4

The practice of performance evaluation can, however, reflect a conflict of binary attributions that "characterize the health field more efficient/inefficient, focus on the patient / focused on the profession, expensive / inexpensive, public/private, and accessible / inaccessible". Therefore, the "performance evaluation of the health system" is never just about performance; it is also discussed as "good" performance, and how this definition will be understood and demanded. 5

It should be emphasized that the evaluation of performance in the health systems arose in a global reform movement context of the State, which questioned its organization and its performance, including the accountability. The nuances that advised these reforms were expenditures containment, the restructured combination of public and private sectors and increase in the user's financial participation in the costing services. In addition to the ideological questions, performance evaluation confirms a desirable and promising practice. 6 Therefore, the usual studied dimensions are insufficient to understand the operation and the results in the health system.

This topic has been widely discussed by the World Health Organization (WHO) on the World Health Report 2000- WHR $2000^{7}$ resulting in The World Health Report 2000 - Health systems: improving performance. This report defines the four main functions in the health system: the financing, the provision of services (whether it is individual or collective), the generation of resources and the management system includes the supervision of components in the public and private sectors of the system. However, the proposed model has received various criticisms, especially regarding the methodology used in the evaluation performance. The WHO would have induced a reform model to take a political and ideological position. 8

In this context, the Organization for Economic Co-operation and Development (OECD), composed of 34 developed countries from different continents, recommended to review the WHO proposal, including indicators of results of the services (microeconomic efficiency), access indicator for to evaluate the equity, the sanitary expenditures (macroeconomic efficiency) and the reference of the evaluation performance analysis of various dimensions. 9

From these discussions, it was suggested that a evaluation performance in the Brazilian health system which would be taken into consideration as the political, social and economic contexts in the country. The dimension of the "health determinants" was subdivided into: environmental; socioeconomics and demographics; behavioral and biological. The dimension of "the population's health conditions" was divided into: morbidity, functional state, wellbeing and mortality. And, the dimension of "the structure of the health system" in: conducting (the government's ability to create and reform health programs), financing and human resources/health technology. 6

The Health Ministry launched in 2011, the Índice de Desempenho do Sistema Único de Saúde (IDSUS) (Unified Health System Index Performance) is composed by 24 indicators, whose goal is to verify its performance as to compliance principles and guidelines. Among the specific objectives are: to evaluate the healthcare network as to the access and the results of actions and services, to identify and evaluate problems and deficits in the system and to be a reference to construct pacts of 
compromises among managers from SUS. 10

The IDSUS attributed a numeric score from 0 to 10 for each city, evaluating the hierarchy (Atenção Primária à Saúde, Cuidados de Média e Alta Complexidade - Primary health care, Care for Medium and High Complexity) of the health system in the axis to have access and effectiveness. The index to access Atenção Primária à Saúde (APS) (primary health care) is measured by the population's estimated coverage from the teams (including oral health), and the proportion of mothers with seven or more prenatal consultations. The index of effectiveness at the APS is measured by: "the proportion of Internações Sensiveis a Atenção Básica (ISAB) (Sensitive Hospitalizations for Primary Care), the incidence rate of congenital syphilis, the proportion of cure in new cases of bacilliferous pulmonary tuberculosis, proportion of cure in new cases of leprosy with a tetravalent vaccine in children under one year of age, an average collective action of supervised tooth brushing and the proportion of dental extraction in relation to the procedures". 10

\section{Regionalization in SUS}

Several studies indicate the fragmentation of health care in Brazil as an important obstacle for ensuring access to timely and quality care. In 2011, a new regulatory mark was established, the Decree Number 7,508, which regulates the Lei Orgânica da Saúde (Organic Health Law), with the objective to reorganize SUS. In this instrument, the legal hierarchically weight superior to the decrees published previously, is established in its 3rd article that "SUS is constituted by a combination of actions and services promotion, protection and health recovery implemented by federal entities, directly or indirectly, through the complete participation of private initiative, being organized in regionalized and hierarchical form". 11

The process of regionalization and the conformation of the care networks can be divided into three phases, with its insertion in the official agenda in the early 2000s. Phase I, from 2001 to 2005 , a strong normative process and little effectiveness. Phase II, between the years 2006 and 2010, the focus was on the integrated and regional networks emphasizing the urgency and emergency service and Phase III, since 2011, brings innovation to the Contrato Organizativo (Organized Contract) for the constitution of regions and healthcare network. 12

Vargas et al.13 in analysis on the regionalization and the healthcare networks in Brazil, mentioned that as a process it presents low implementation and development, because it depends on a weak negotiation among managers responsible for the complex regional entity and the fragile co-responsibility of the State and Federal levels. The authors suggest the urgent need to strengthening regional structure and healthcare networks.

Knowing about this, we elaborated some questions, such as: is it possible to create a synthetic indicator of a regional performance to evaluate the respective health systems?; the parameters that are going to be used, do they have easy access and are allowed to compare with other regional systems? Thus, this study aims to propose an indicator to evaluate the performance in the health system in the Brazilian regions based on a national database source available free of charge in the global network of computers.

\section{Methods}

This is a cross- sectional study using secondary data obtained from the Departamento de Informática do Sistema Único de Saúde do Brasil (DATASUS) (Department of Informatics of the Public Health System) for the 438 health regions in Brazil. To organize the data, we used Microsoft ${ }^{\circledR}$ Office Excel ${ }^{\circledR}$ software, given its functionality in generating data. The map was created with the use of Maptitude 5.0 applicative (Caliper Corporation, Newton, MA).

The research "Politica, Planejamento e Gestão das Regiões e Redes de Atenção à Saúde no Brasil" (Policy, Planning and Management in Regions and Healthcare Networks in Brazil) seeks to identify and evaluate conditions that are easy or difficult to process regionalization and the conformation of Redes de Atenção à Saúde (Healthcare Networks) in the Country. The research has as its objective factors that promote the universalized health in Brazil, among which the regionalization would be a fundamental strategy to guarantee this ethical and doctrine principle. 14

The research selected 17 regions for the sample from a qualitative analysis of determined criteria that expressed the diversity of socioeconomic, territorial and the existing health system situations. In relation to the territorial criteria were considered all the macro-regions, the interstate borders areas, regions with cities belonging to QualiSUS and Saúde Amanhã (Health Tomorrow) projects. ${ }^{14}$

According to the typology of the health regions proposed by Viana et al.,15 models were adopted for factorial and cluster analysis in which the socio- 
economic development, the offering and the health services complexity in the regional context were considered as structural constraints to the regionalization in Brazil. From this methodology, the health regions were grouped into five strata defined in the form below:

- Group 1 - low socioeconomic development and low service offerings

- Group 2 - middle/high socioeconomic development and low service offerings

- Group 3 - middle socioeconomic development and medium/high service offerings

- Group 4 - high socioeconomic development and medium service offerings

- Group 5 - high socioeconomic development and high service offerings

The synthetic indicator of performance for the health system regions was constructed with variables that follow Viana's et al.15 proposal of cluster analysis and the OECD. 9

The inclusion criteria for the OECD indicators were related to the parameters that could measure a population's health and costs, the scientific evidence are comparable to the data from other countries. Among the selected indicators are: life expectancy at birth, death rate due to cardiovascular diseases, a proportion of the population that are smokers, a proportion of the population that consumes alcohol, the proportion of the population that are overweight/obesity, type of health coverage, health expenditures per capita, physicians and nurses per capita, hospital beds per capita, computed tomography per capita, presence of geographical barriers to access medical and dental consultations, waiting time for cataract surgery, number of hospitalizations due to asthma or chronic obstructive pulmonary disease (COPD), mortality rate due to acute myocardial infarction (IAM), mortality rate of ischemic stroke, survival rate of cervical,/breast/ colorectal cancer. $^{9}$

In this study, the variables were adjusted according to their availability in the DATASUS and selected those that could estimate the populations' health status in health regions in Brazil. The variables were divided into five dimensions considered to be important for the Brazilian scenario: the populations' health conditions, health system coverage, financing, human resources and production from SUS. Among the chosen variables, the infant mortality rate was calculated using the total number of infant deaths in the health region over the total number of live births in this same region. The mean rates in the cities were not calculated.

The collection of variables in the DATASUS and the elaboration of the ISR occurred during 2015. However, the variable "infant mortality rate" was calculated in 2011 to 2013 . The variable "per capita expenditure in health" corresponded in 2013, because during the period of elaborating this proposal, the performance indicators in health regions in Brazil, the rate was still not available in the data source in 2014.

Following the rate of each variable for its health region and the mean in Brazil for the same variable, performed scores of [ 0 ] to the dimensions with lower scores than the average in the Country and [1 ] if the index is better than the national average. In Table 1 the variables are presented in their respective dimensions and the value to be marked.

The regional synthetic indicator (ISR) represents the sum of the components of five dimensions with an interval of [0.5]. The higher the value is obtained, the better the performance of the system. Thus, the value of zero represents the worst performance and the value 5, the best. For the selected regions, it was proposed to analyze not only the ISR, but also the different indicators that it composes.

The regional synthetic indicator was developed for the 438 health regions in Brazil. The data were analyzed and clustered for the proposal of the indicator according to their availability in the data source from the Ministry of Health. After creating the ISR, three models for descriptive data analysis and result presentation were developed: 1) Mapping of 438 health regions based on ISR; 2) Crossing of ISR with the typology of 438 health regions and their structural determinants proposed by Viana et al.15; and 3) Presentation of the detailed data according to the 17 health regions chosen in the research "Política, Planejamento e Gestão das Regiões e Redes de Atenção à Saúde no Brasil" (Policy, Planning and Management in Regions and Healthcare Networks in Brazil).

This study was registered on the Plataforma Brasil (Brazil Platform) CAAE: 42787815.9.1001.0065 and approved by the Research Ethics Committee at the Faculdade de Medicina da Universidade de São Paulo, Brazil, according to the Protocol number 071/15, in accordance with the Resolução do Conselho Nacional de Saúde (National Health Council Resolution) Number $466 / 12$.

\section{Results}

A map was constructed with their respective ratings of ISR and scheduling in health regions in Brazil (Figure 1). There are four regions with the highest 
Dimensions and variables of the regional synthetic indicator, 2015.

\begin{tabular}{lrl}
\hline Dimensions & Variables & Value of the indicator (for Health Region) \\
\hline $\begin{array}{l}\text { The Population's Health } \\
\text { Conditions }\end{array}$ & "Infant mortality rate - in 1,000 & $\begin{array}{l}\text { Equal to one if rate is less than or equal to } \\
\text { what is observed in Brazil, otherwise zero. }\end{array}$
\end{tabular}

Health System Coverage

"Populational coverage estimated by the Primary Care team (December/2014)"

Financing

"Expenditures per capita on health (2013)"

Human Resources

SUS Production
"Physicians per thousand inhabitants (December/2014)"

" SUS Outpatient production per thousand inhabitants (2014) "

"Outpatient production percentage of public provider in the total of the outpatient clinic production (2014)"

" Hospitalizations percentage due to public provider in the total hospitalizations (2014)"
Equal to one if it is greater than or equal to what is observed in Brazil, otherwise, zero.

Equal to one if the expenditure per capita on health is greater than or equal to what is observed in Brazil, otherwise, zero.

Equal to one if it is greater than or equal to what is observed in Brazil, otherwise, zero.

For each of the three variables, receive the score of 0.33 if the value is greater or equal to what is observed in Brazil, in such a way that the sum obtained for the three indicators varies in a range of [0.1]. Otherwise, the value will be zero. 


\section{Figure 1}

Map of health regions in Brazil scheduling with the regional synthetic indicator, 2015.

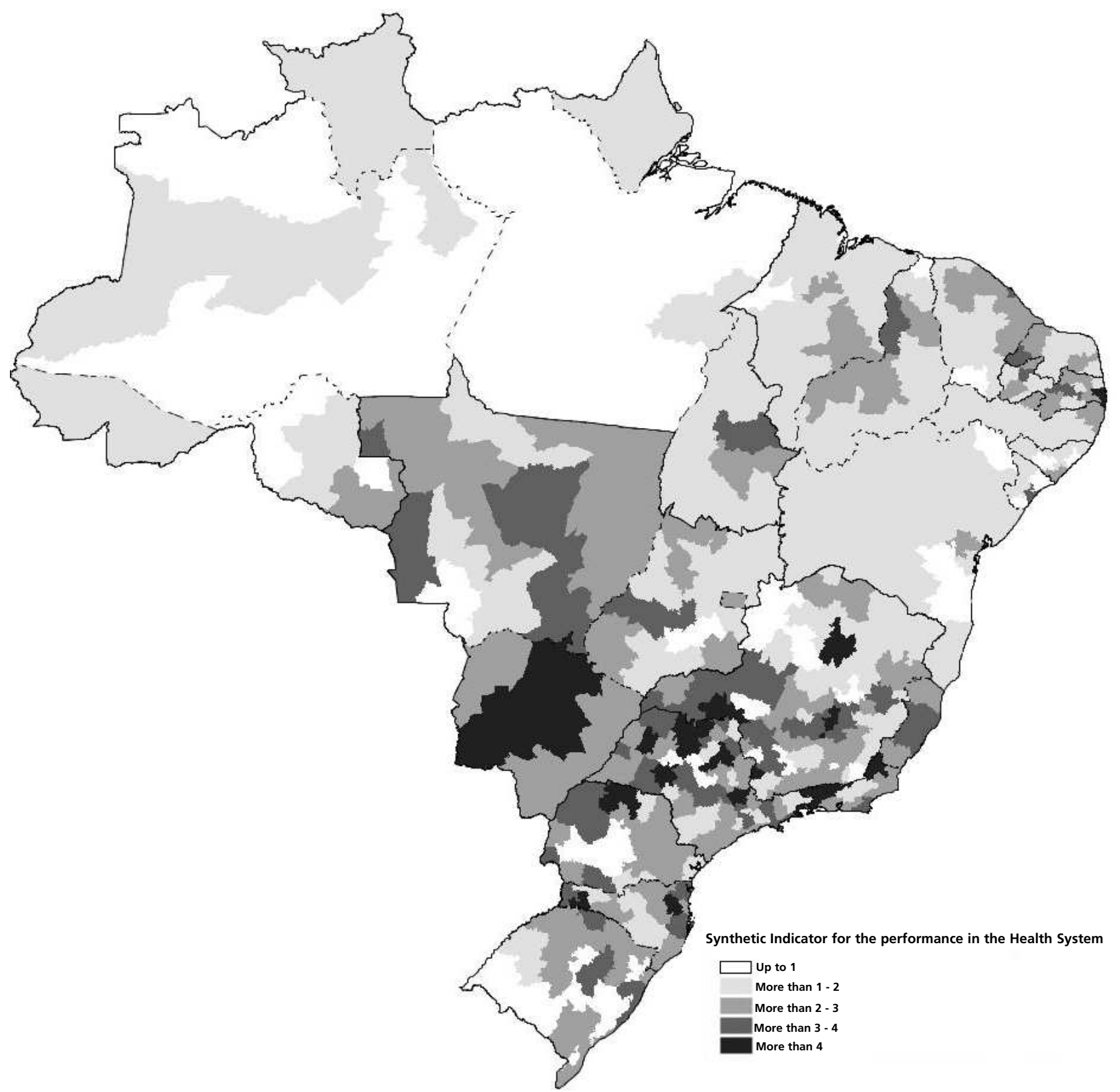


Values of the average, minimum and maximum of the regional synthetic indicator for regional groups in health regions according to the typology of the health regions, 2015.

\begin{tabular}{ccccc}
\hline Typology of the health regions & N (regions) & Average & Minimum & Maximum \\
\hline 1 & 175 & 1.71 & 0.00 & 3.67 \\
2 & 47 & 2.22 & 0.00 & 4.00 \\
3 & 129 & 2.51 & 0.00 & 4.67 \\
4 & 27 & 2.67 & 0.33 & 4.67 \\
5 & 60 & 3.42 & 0.00 & 5.00 \\
Total & 438 & 2.29 & & 5.00 \\
\hline
\end{tabular}

\section{Figure 2}

Regional Synthetic Indicator by health regions according to the typology in health regions, 2015.

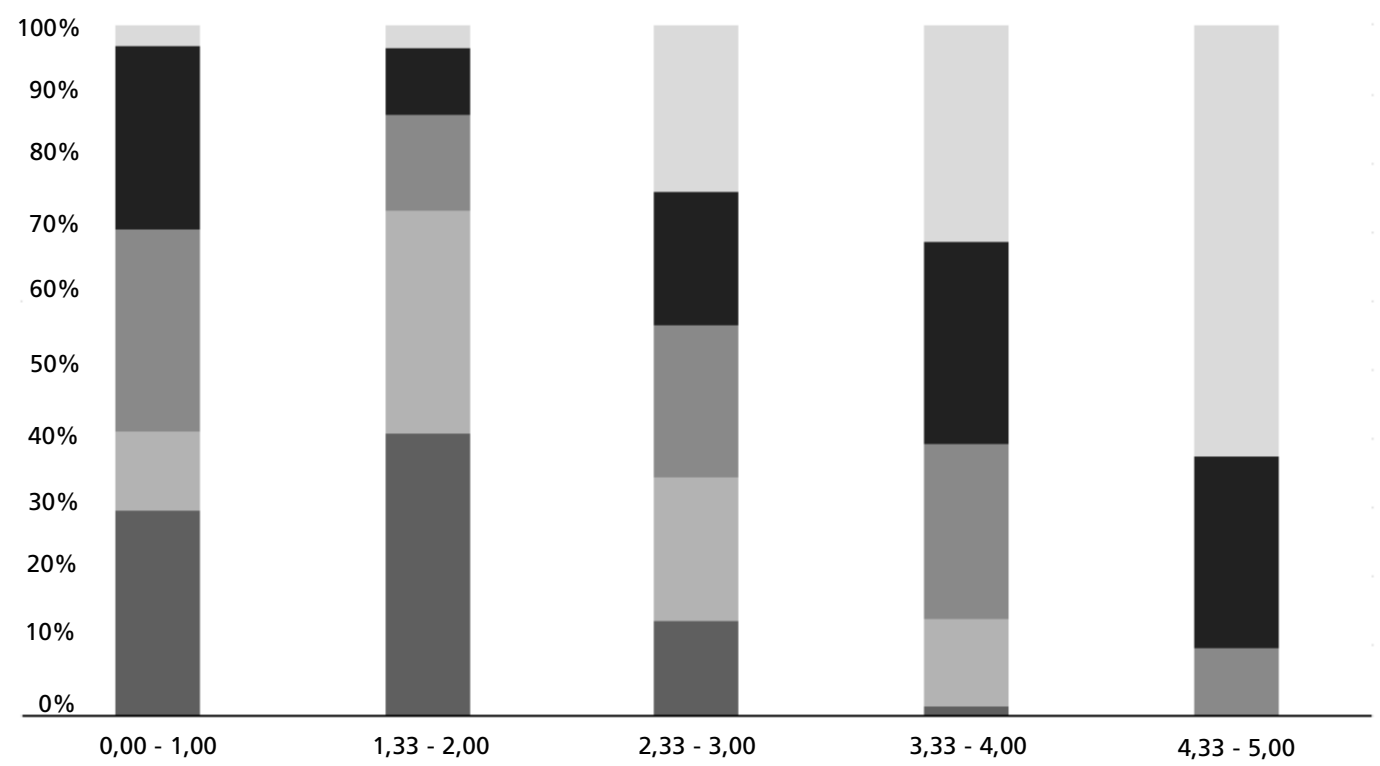

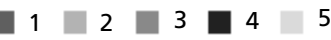




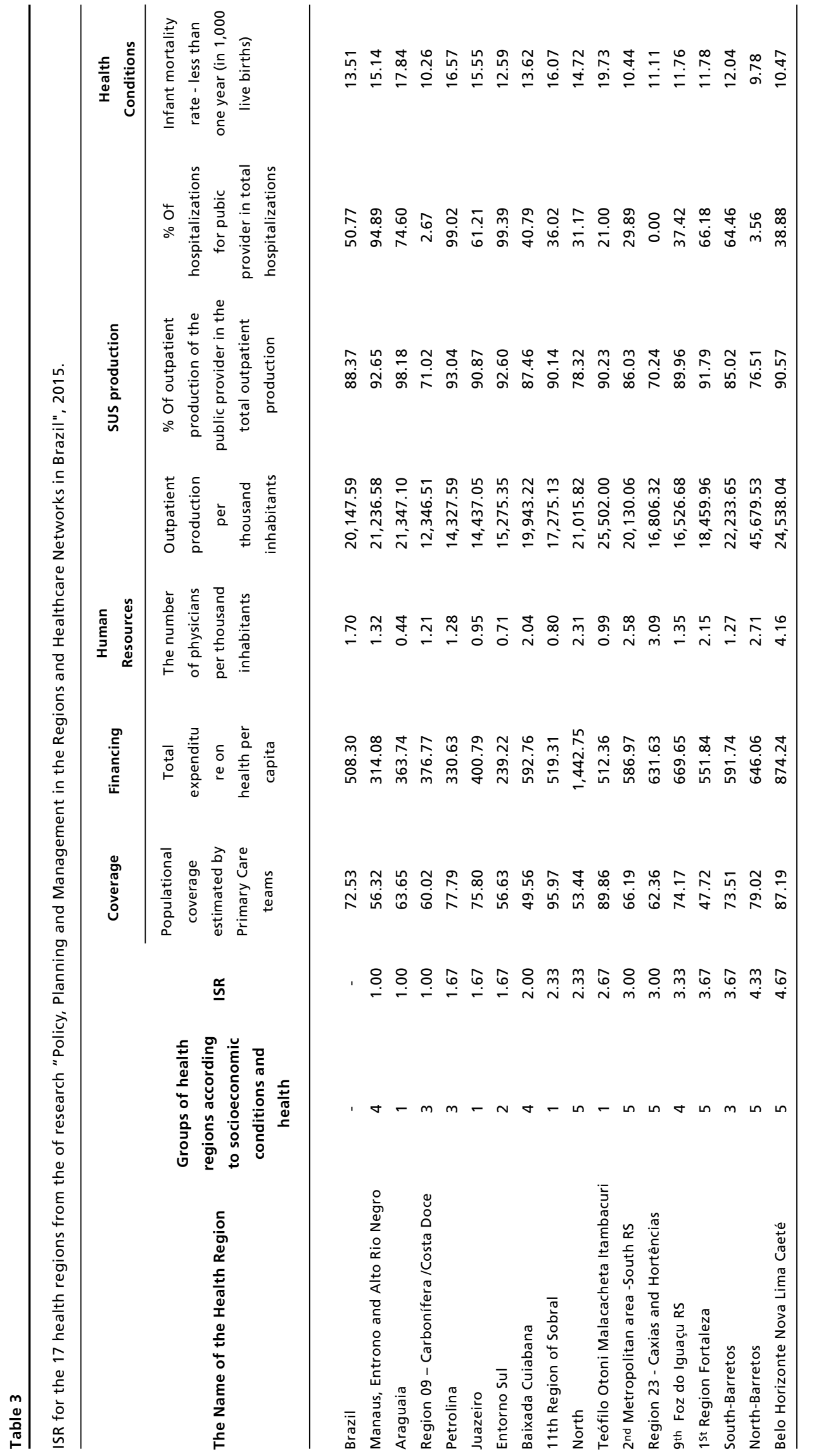


score [5] of ISR: Metropolitan Region of Campinas (SP), Aquífero Guarani (SP), Central DRS III (SP) and the 17th Health Region in Londrina (PR). And, five with minimum score [0]: Region 3-Fronteira Oeste (RS), Region 22-Pampa (RS), Centro Sul (GO), Oeste Matogrossense (MT) and Ilhéus (BA).

Table 2 presents health regions into cluster analysis according to the typology in health regions proposed by Viana et al.,15 as well as the mean for the synthetic indicators and maximum and minimum values.

However, there is a tendency for the increase of the average when the standard group of typology increases. There is an approach between the regional synthetic indicator and the established typology, demonstrating that the higher the indicator values the higher is the probability of this health region to be present in a high typology (Figure 2). It can be noticed on the following results per region strata:

- Group 1: includes 175 regions, 2,151 cities and $22.5 \%$ of the population in Brazil in 2015, are mainly located in the Northeast.

- Group 2: includes 47 regions, 482 cities and $5.7 \%$ of the population in Brazil. Most of these regions are located in the Midwest, Southeast and North regions.

- Group 3: includes 129 regions, 1,891 cities and $20.3 \%$ of the population in Brazil in 2015, are mainly located in the Southeast and South regions.

- Group 4: includes 27 regions, 300 cities and $10.6 \%$ of the population in Brazil in 2015, most of them are located in the Southeast region.

- Group 5: includes 60 regions, 746 cities and $40.9 \%$ of the population in Brazil in 2015, are mainly located in the Southeast and South regions.

In Table 3 demonstrates the ISR data and the respective variables for health regions of the research sample. It is observed that the regions with lower values of ISR have worse performance in the dimensions of coverage, financing, human resources and health conditions. All the regions with the ISR less than 2 presented performance below the National average in at least three of the four listed above. On the other hand, regions with ISR greater or equal to 2 and less than 4 showed worse performance in both dimensions listed as the dimension of SUS production.

When performing the same standard of analysis based on the typology in health regions it is notable that, the greater the development (groups 4 and 5), the lower the degree of population coverage according to the Estratégia de Saúde da Família (FHS) (Family Health Strategy) (dimension coverage) and the lower the rates of SUS production indicators, leading to a no score on these ISR issues. In the regions representing groups 1, 2 and 3 of the typology, presents dispersion in the dimensions that would lead to losing points.

\section{Discussion}

This study reinforces the proposal to construct a regional synthetic indicator to for analysis the performance of a health system in health regions in Brazil. The parameters selected to compose the ISR are of easy access for the administrators and managers in the health services. The selection of these parameters is according to an experience of Tuscany, Italy, in which a set of potential indicators were chosen according to the literature review, reference to the National, regional and sub-regional system, in addition to the discussions among different professionals in the construction of a panel of indicators. Thus, the authors recommend a conference of indicators by an experienced group in evaluation, suggesting in this case, by a public university without links with the provision of regional system. 16

According to the ISR results proposed in this study, it was observed that this new instrument for performance evaluation in health regions is found in according to other authors proposal.6,16,17 Most regions belong to group 1 of the typology in health regions in which obtained the lowest score of the ISR (1.7162) and are located in the macro-regions of the North and Northeast of the Country. However, most of the population resides in areas which scored the best ISR parameters.

The comparison suggested with the typology of regions proposed by Viana et al. ${ }^{15}$ demonstrated to be a methodology that increases the performance evaluation in the health systems, because it aggregates indicators of structure, process and results. The data presented emphasizes the importance of integrated public policies for regional development because the relation among socioeconomic development, provision of services and the performance in health care system.

The results presented by Pavão et al., ${ }^{17}$ suggest that there is a relation among socioeconomic characteristics, resources and the performance in health systems in the researched regions. The developed regions have better conditions and structure to attend the population, demonstrating the regional inequality, a situation which corroborates the data found in this study. Another similarity among these studies is the inequality found among regions in the North and Northeast when compared to those in the 
Southeast and South.

The use of the National database for planning interventions in health care has been a practice most often used in the recent years in which these data were only used for service management or disease control. ${ }^{6}$ However, the fragmentation, duplication and the slow process of updating the information systems may hinder the development of health actions and the performance evaluation of the services. 18

According to Pereira and Tomasi, 19 in Brazil a system of a unique regional and integrated information is still in the process of construction. The authors emphasize that the analysis of the indicators may aggregate values to the qualification in health actions for managers, which meets the objective of this study. However, different from the study mentioned above 19 which allows the exchange of indicators to analysis the regional health system, this proposes a regional indicator with standardized variables that assisted in the comparisons with other health regions and in decision-making.

Duarte et al.20 confirm that to evaluate the performance in the regional health system by human development, using well established indicators and aggregation methods, favors the comparative analysis within the health regions.

The variable of amenable mortality has been used in some studies to compare different Countries, States, urban and rural areas, however, it does not have reliable evidence for health regions, following the example in Canada. It was verified that, in spite of being an easy understandable variable it has a strong correlation with a vast causes of mortality, but not evaluating the performance of the system. And, in addition, the variable shows location that provide high-quality care, while masking external factors that contribute to accentuate the inequalities in health. 21

A proposal to analyze the coverage of the health system was performed in a study on regional diversities among the 21 regions in Tanzania, East Africa: the density of Health Units per 10,000 inhabitants, beds per 10,000 inhabitants, physicians per 10,000 inhabitants, nurse-midwives per 10,000 inhabitants, number of hospitalizations per 100 inhabitants per year and the number of visits to outpatient clinics per year. Thus, it was observed that to work in the regional area is preferable than in the District /State, either to analyze the coverage as to analyze the performance of the local health system. 22

The GDP per capita variable is used frequently as a gold standard in the performance evaluation in the health systems, however, if it was analyzed in an isolated form, it does not represent environmental sustainability, nor does the social inclusion, as determinants in the population. The life expectancy at birth, death rate and infant mortality rate variables are considered important indicators in evaluating the results of a system. In analysis of the performance of the NUTS-2 group (Nomenclature of territorial units for statistics), an economic division of the European Union with 276 regions, the number of physicians per 100,000 inhabitants was used, an input nondiscriminatory variable as GDP per capita, and the outcome variables used were the life expectancy and infant mortality rate. The performance and efficiency were not determined by the level of financing in the regions that had better results, Sterea Ellada and Thessaly (Greece), Extremadura (Spain), Alanda (Sweden), North (Portugal) and Zealand (The Netherlands). 23

Brown et al.24 recommend for an efficient health system, it is necessary to exist specific objective with plans and aims to be achieved, along with frequent reports with the results of improvement and, especially, with the participation of medical professionals in this discussion aligned to the same targets.

Based on regional experiences in Valencia, Spain, and Tuscany, Italy, it was concluded that an objective definition and clear targets, as well as how the results are evaluated interfere in a better performance of governance and regional indicators. In this study, the authors suggest that the benchmarking is a valid support for a better performance. 25

According to Aristovinik, 23 there is an absence in the literature on studies about evaluation in regional health systems. For the author, to measure the effectiveness of these regional systems continues to be complex, due to its particular characteristics of available socioeconomic resources.

\section{Conclusion}

This article sums the efforts of other authors to extend the studies on evaluation in health systems at regional level. In addition, it is expected that the research broaden its scope and implement discussions about the regionalization process in order to provide health policies, the universalized access and comprehensiveness of care.

The empirical findings indicate better performance for the health systems in regions in Brazil located in the macro-regions of the Southeast, South and Midwest. A large part of the North and Northeast in Brazil presents low performance, except the regions that cover the capitals of the Northeastern 
States. The regions, Region 3 - Fronteira Oeste (RS), Region 22 - Pampa (RS), Centro Sul (GO), Oeste Matogrossense (MT) and Ilhéus (BA) do not indicate in any ISR variables, thus, presenting a low score when compared to the Brazilian average in all the criteria.

The proposal of the synthetic indicator for the regions in Brazil, elaborated by the research "Política, Planejamento e Gestão das Regiões e Redes de Atenção à Saúde no Brasil" (Policy, Planning and Management of Regions and

\section{References}

1. Roemer M. National Health Systems of the World. (Vol.1: The Countries). Inglaterra: Oxford University Press; 1991.

2. Donabedian A. The quality of care. How can it be assessed? JAMA. 1998; (260):1743-8.

3. Klazinga N. Health system performance management: Quality for better or for worse. Eurohealth. 2010; 16 (3): 26-8.

4. Champagne F, Contandriopoulos AP, Brouselle A, Hartz Z, Denis J. A avaliação no campo da saúde: conceitos e métodos. In: Broussele A, Champagne F, Contandriopoulos AP, Hartz Z (Orgs.). Avaliação em saúde conceitos e métodos. Rio de Janeiro: Fiocruz; 2011. p. 19-40.

5. Lynch T. A Critique of Health System Performance Measurement. Int J Health Serv. 2015; 4 (4): 743-61.

6. Viacava F, Almeida C, Caetano R, Fausto M, Macinko J, Martins M, Noronha JC, Novaes HMD, Oliveira ES, Porto SM, Silva LMV, Szwarcwald CL. Uma metodologia de avaliação do desempenho do sistema de saúde brasileiro. Ciênc Saúde Coletiva. 2004; 9 (3): 711-24.

7. OMS (Organização Mundial da Saúde). The World Health Report: Health System: Improving Performance. Genebra; 2000

8. Almeida CM, Braveman P, Gold MR, Szwarcwald CL, Ribeiro JM, Miglionico A, Millar JS, Porto S, Costa NR, Rubio VO, Segall M, Starfield B, Travassos C, Uga A, Valente J, Viacava F. Methodological concerns and recommendations on policy consequences of the World Health Report 2000. Lancet. 2001, 357(9269): 1692-7.

9. OECD - Health Care Quality Indicators Project: Conceptual Framework Paper. OECD Health working papers, n. 23, 2006. Disponível em: http://www.oecd.org/els/healthsystems/36262363.pdf

10. Brasil. IDSUS, Índice de Desempenho do Sistema Único de Saúde. Ministério da Saúde, Brasil. Disponível em: http://idsus.saude.gov.br/grupos.html. [acesso em $14 \mathrm{fev}$ 2016].

11. Brasil. Presidência da República. Ministério da Saúde. Decreto n. 7.508 de 28 de junho de 2011. Regulamenta a Lei 8.080, de 19 de setembro de 1990, para dispor sobre a organização do Sistema Único de Saúde (SUS), o planejamento da saúde, a assistência à saúde e a Diário Oficial da
Healthcare Networks in Brazil), sought to present a resource for easy monitoring and evaluating the performance in health systems by regions, according to the current health policy in the Country and it can assist managers in regional planning in actions and health services.

The limitations of this study are related to the difficulty in obtaining data in the same period, as it is the case of infant mortality rate and also the expenditures per capita on health. This delay in the information process could jeopardize the elaboration
União articulação interfederativa, e dá outras providências. Diário oficial da União, Brasília (DF). 2011, 29 jun.

12. Albuquerque MV, Viana ALD. Perspectivas de região e redes na política de saúde brasileira. Rev Saúde e Debate, 2015. 39: 24-34.

13. Vargas I, Mogollón-Pérez AS; Unger J. Regional-based Integrated Healthcare Network policy in Brazil: from formulation to practice. Health policy and planning. 2014. 3:705-717.

14. Região e Redes: o caminho da universalização da saúde no Brasil. Disponível em: http://www.resbr.net.br

15. Viana ALD, Bousquat A, Pereira APCM, Uchimura LYT, Albuquerque MV, Mota PHS, Demarzo MMP, Ferreira MP. Tipologia das Regiões de Saúde: condicionantes estruturais para a regionalização no Brasil. Saúde Soc. 2015; 24 (2): 413-22.

16. Li H, Barsanti S, Bonini A. Building China's municipal healthcare performance evaluation system: A Tuscan perspective. Int J Qual Heal Care. 2012; 24 (4): 403-10.

17. Pavão AL, Duarte CR, Viacava F, Oliveira RAD. Aspectos Socioeconômicos, de Estrutura e de Desempenho dos Serviços de Saúde das 17 Regiões de Saúde do Projeto Região e Redes. Novos Caminhos, n.7. Pesquisa Política, Planejamento e Gestão das Regiões e Redes de Atenção à Saúde no Brasil. Disponível em http://www.resbr.net.br/ wpcontent/uploads/2015/12/NovosCaminhos7.pdf

18. Hovenga EJ. National healthcare systems and the need for health information governance. Stud Health Technol Inform. 2013; 193: 3-23.

19. Pereira $\mathrm{B}$ dos $\mathrm{S}$, Tomasi E. Instrumento de apoio à gestão regional de saúde para monitoramento de indicadores de saúde. Epidemiol Serv Saúde. 2016; 25 (2): 411-8.

20. Duarte CMR, Pedroso MM, Bellido JG, Moreira RS, Viacava F. Regionalização e desenvolvimento humano: uma proposta de tipologia de Regiões de Saúde no Brasil. Cad Saúde Pública. 2015; 31 (6): 1163-74.

21. Lavegne MR, McGrail K. What, If Anything, Does Amenable Mortality Tell Us about Regional Health System Performance? Healthc Policy. 2013; 8 (3): 79-90. 
22. Kumalija CJ, Perera S, Masanja H, Rubona J, Ipuge Y, Mboera L, Hosseinpoor AR, Boerma T. Regional Differences in Intervention Coverage and Health System Strength in Tanzania. Plos one. 2015; 10(11): e0142066.

23. Aristovinik A. Regional Performanc Measurement of Healthcare Systems in the EU: A Nonparametric Approach. Lex localis - J Local Self-Government. 2015. 13 (3): 579 93.

Received on May 29th, 2017

Final version presented on July $6^{\text {th }}, 2017$

Approved on September 18th, 2017
24. Brown A, Closson T, Sullivan T, Baker GR. The journey toward high performance and excellent quality. Healthc Q. 2012; 15: 6-9.

25. Vainieri M, Vola F, Gomez Soriano G, Nuti S. How to set challenging goals and conduct fair evaluation in regional public health systems. Insights from Valencia and Tuscany Regions. Health Policy. 2016; 120 (11): 1270-8. 